\title{
DC Fault Ride Through of Multilevel Converters
}

\author{
Geraint Chaffey, Paul D. Judge, Michaël M. C. Merlin, Philip R. Clemow and Timothy C. Green \\ School of Electrical and Electronic Engineering \\ Imperial College London \\ London, UK \\ Email: g.chaffey12@imperial.ac.uk
}

\begin{abstract}
Modular Multilevel Converters (MMC) can provide significant advantages for power transmission applications, however there are remaining challenges trading off DC fault response, losses and controllability. Alternative multilevel converter topologies using combinations of full bridge and half bridge submodules or series switches allow for competitive efficiency whilst retaining control over the DC fault current. Several possible fault responses are analysed to evaluate appropriate converter control actions. Experimental results from a 60 submodule $15 \mathrm{~kW}$ demonstrator are presented to validate the DC fault performance of the full bridge MMC, the mixed stack MMC and the alternate arm converter. It is shown that each can control the current into a low impedance DC fault, and there no requirement to block the semiconductor devices.
\end{abstract}

\section{INTRODUCTION}

Bulk power transmission through subsea cables and over long distances is commonly achieved using HVDC, however the majority of installed systems are in the form of point to point links. There has recently been increased research and development efforts towards the development of multi-terminal HVDC networks, which would enable better sharing of disparate renewable energy sources. Technical and economic challenges however remain, in particular when considering the protection of such a system (faults on HVDC systems are challenging due to the steep rate of rise in current), whilst maintaining low loss power transfer and economic viability. Fast hybrid HVDC circuit breakers are presently under industrial test [1]-[3], however their economic feasibility is yet to be established.

When considering an HVDC network there are several strategies to protect against DC faults; AC circuit breaker isolation, implementing DC circuit breakers, or using fault current limiting converter topologies. Fault current limiting converters may lead to a significant reduction in the requirement for fast DC circuit breakers [4], and are also particularly attractive for systems implementing overhead lines where the rate of nonpermanent faults is relatively high [5].

Several converter topologies are presented in Fig. 1. The Modular Multilevel Converter (MMC) is an attractive method of conversion between AC and DC, providing low loss operation with flexible reactive power and minimal filtering requirements. The Half Bridge MMC (HB MMC), which is presently the most commercially attractive topology for flexible subsea interconnection, feeds an uncontrolled current into a low impedance DC fault through the lower diodes in each SubModule (SM). Several other topologies have been proposed to address this challenge, each capable of controlling the current into a DC fault. There are several proposed SM topologies, Fig. 1a, with various arrangements of switching devices. The Full Bridge MMC (FB MMC) consists of full bridge SMs, therefore the number of IGBTs is doubled and the losses are increased accordingly. Alternative multilevel converter topologies combining elements of half bridge MMCs, full bridge MMCs, and two level converters have also been proposed to improve the efficiency whilst retaining the DC fault capabilities of full bridge converters. The Mixed Stack MMC (MS MMC) combines half bridge and full bridge SMs to reduce the losses compared to the FB MMC whilst retaining enough over-modulation capability to maintain current control following a DC fault. The Alternate Arm Converter (AAC) combines full bridge SMs and a series stack of IGBTs (termed 'director switches') to control the conduction state of each arm, whilst remaining competitive regarding losses, size, and number of devices [6].

The following sections discuss converter responses to low impedance DC faults and present experimental results from the FB MMC, the MS MMC and the AAC under DC fault conditions.

\section{Feasibility of DC Fault Responses for Fault CURRENT LIMITING CONVERTERS}

Whilst it has been suggested that the IGBTs in a full bridge SM should be blocked during a DC fault [7]-[10], full current control can still be achieved using appropriate control algorithms [5], [11]-[13]. It may be beneficial to maintain full control over the converter, in particular so that the SM capacitor voltages remain balanced and the converter remains ready to immediately resume power transfer. The provision of reactive power support may also be of benefit to the AC system, with the converter acting as a STATCOM throughout any DC fault event, aiding the stability of the AC system during the loss of infeed.

The fundamental control aims under DC fault conditions are to protect the SM IGBTs from overcurrent and the SM capacitors from overvoltage, therefore protecting the converter from damage. Additionally it may be beneficial to the connected AC system to provide reactive power support in a STATCOM mode. Both the AC and DC systems are likely to benefit from a timely post-fault recovery in the event of a transient fault or a network fault that is cleared by a DC circuit breaker. 


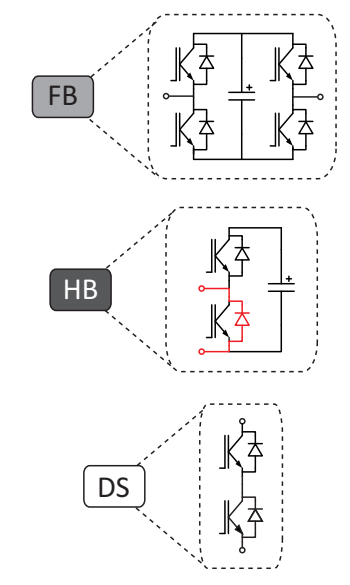

(a) Submodule topologies

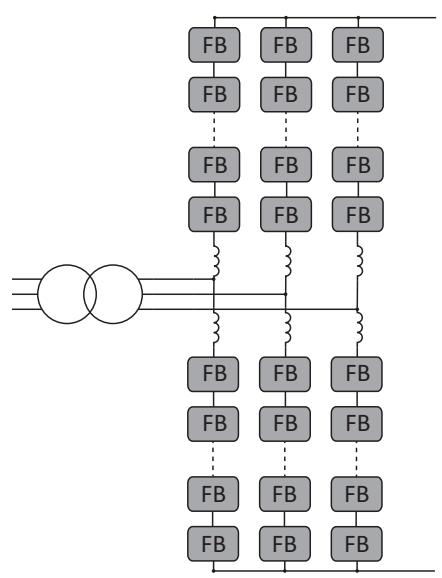

(b) Full bridge MMC

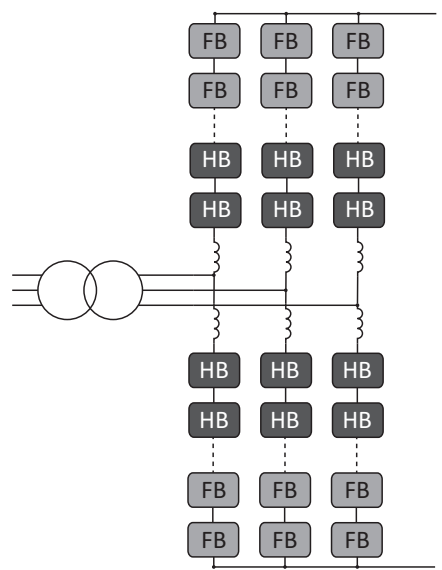

(c) Mixed stack MMC

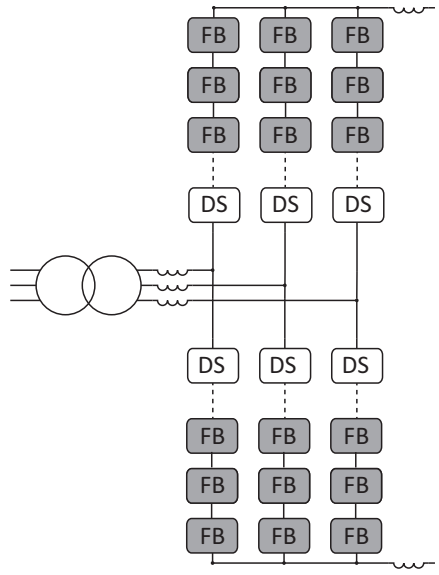

(d) Alternate arm converter

Fig. 1: Multilevel converter topologies with DC fault current limiting capabilities

The multilevel converter topologies under examination are able to control the current into a DC fault given their ability to use full bridge SMs to insert the SM capacitor in negative orientation. By generating both positive and negative arm voltages the converter is able to oppose the line-to-line AC voltage, maintaining current control during the fault. When all the IGBTs within a full bridge SM are blocked, the SM naturally blocks a voltage of the same magnitude as the charged SM capacitor (as opposed to a half bridge SM which blocks a voltage of the magnitude of the charged SM capacitor in one polarity, but conducts in the other polarity due to the diode in the lower IGBT).

A converter with a sufficient number of full bridge SMs to oppose the AC line to line voltage therefore naturally blocks any steady state fault current, however when the IGBTs across the converter are blocked, the fault current continues to flow through the freewheeling diodes and the SM capacitors until the stored energy in the arm inductors is discharged. This uncontrolled current could lead to small amounts of charging and discharging of SM capacitors, potentially leading to a requirement for SM overvoltage protection [8].

Given that full bridge SMs are able to be controlled to generate a negative voltage there is no inherent requirement to block the IGBTs. With appropriate control of the SMs the converter can remain in control of the currents, assuming that the SMs remain charged and the arms can therefore generate sufficient negative voltage. The converter remains switching and therefore can continue balancing the SMs and remains stable in this operational state indefinitely.

The faults shown in the following sections explore pole-topole low impedance DC faults, exhibiting the highest fault currents. The currents experienced during pole-to-ground faults are highly dependent on the earthing of the converter and the DC network; if the converter is earthed through a low impedance then the converter currents will be similar to a pole-to-pole fault, whereas high impedance converter earthing will exhibit lower fault currents but higher voltage stresses and therefore a higher requirement for overvoltage protection on the cable or overhead line.

There are several possible control and protection responses that a fault current limiting converter could have following a fault, discussed in the following sections.

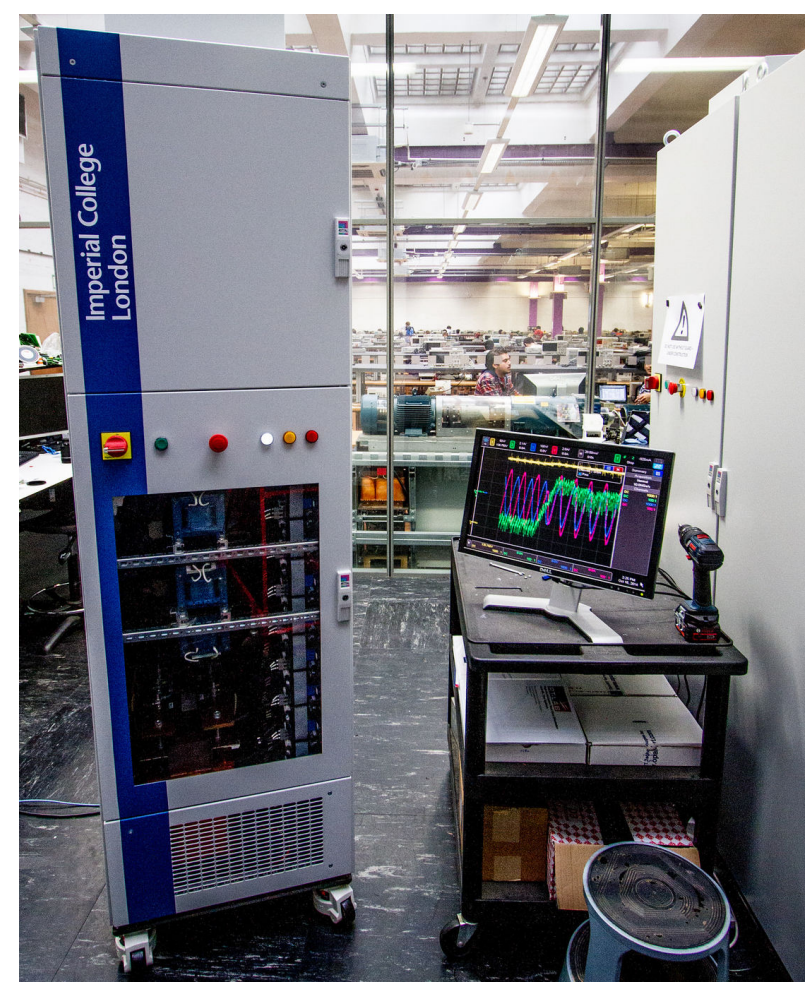

Fig. 2: Experimental setup

\section{A. AC Circuit Breaker Isolation}

The most simplistic DC fault response is to order the opening of the AC circuit breaker immediately after the fault is detected. This does not isolate the converter immediately, 


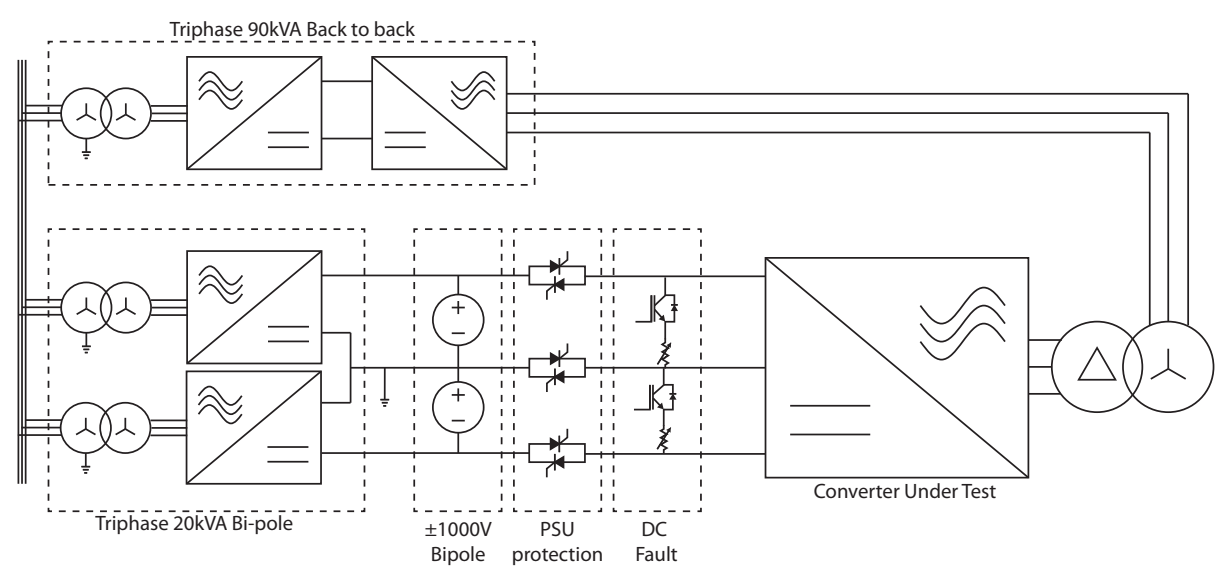

Fig. 3: Lab scale demonstrator hardware setup

given that there is delay of several fundamental $\mathrm{AC}$ cycles for a typical AC circuit breaker operation. During this period the state of the converter depends on the control, however it might be expected that the IGBTs would be blocked, given the convention when operating HB MMCs.

Some control schemes for this mode of operation do not maintain current control before the $\mathrm{AC}$ circuit breaker isolation [7], leading to a current contribution from the AC-side and/or SM capacitors into the fault. This mode of operation could therefore cause unnecessary disturbances to the connected AC network and the SM capacitor voltages.

\section{B. Isolation by Blocking of IGBTs}

Following the convention from HB MMCs, some sources suggest blocking the IGBT gates upon detection of a DC fault. Whilst this does not damage the converter, it has several potential downsides when compared to continuing the switching operation. No reactive power can be supplied to the AC network, and the SMs will slowly discharge therefore following a long fault a recharging procedure would be required.

Operating a converter in this mode does not utilise the full capability of the converter during a DC fault, and may allow the SM capacitances to become discharged. Current control is lost by the converter in this mode, again leading to the possibility of disturbance to the AC network and SM capacitors, in some cases requiring high energy protection measures to avoid SM overvoltage [8].

\section{Control Current to Zero}

Given that the converters under consideration are capable of maintaining current control into a low voltage DC event such as a DC fault, the typical control action in the event of a DC fault would be to control the current to zero. Not feeding any fault current from the converter will allow any DC circuit breakers or disconnectors to operate under low stress conditions, and in the event of an overhead line fault de-ionisation will be allowed to occur [5].

Remaining synchronised and connected to the AC system allows the converter to operate in a STATCOM mode, providing support to the connected AC system, and allowing power transfer to resume quickly once the fault has been cleared. SM capacitors remain charged at all times as the converter remains stable and draws balancing currents from the AC-side.

\section{Control Current into Fault}

It may be beneficial to protection systems to feed a controlled current into the fault, for example when using a slower differential discrimination system. Converters are also able to feed a small current into the DC network, and determine if a fault is still present based on the voltage rise. This discrimination technique is used in the hardware converters in the following section.

\section{EXPERIMENTAL VALIDATION OF MULTILEVEL CONVERTER DC Fault Ride Through}

In order to experimentally verify simulation results a labscale converter has been built, consisting of 60 SMs that can each be configured as a half bridge or a full bridge, and director switches [13], [14]. The converter can therefore be run as a half bridge, full bridge or mixed stack MMC, or as an AAC, as specified in Table I. The laboratory setup includes additional auxiliary converters and power supplies to emulate the $\mathrm{AC}$ and $\mathrm{DC}$ connections for the converter under test, Fig. 3. This allows for a range of synthetic and hardware

\begin{tabular}{cccc}
\hline & FB-MMC & MS-MMC & AAC \\
\hline $\mathrm{V}_{\mathrm{DC}}$ & $1500 \mathrm{~V}$ & $1500 \mathrm{~V}$ & $1500 \mathrm{~V}$ \\
$\mathrm{I}_{\mathrm{DC}}$ & $10 \mathrm{~A}$ & $10 \mathrm{~A}$ & $10 \mathrm{~A}$ \\
$\mathrm{~V}_{\mathrm{AC}}$ & $800 \mathrm{~V}$ & $800 \mathrm{~V}$ & $1170 \mathrm{~V}$ \\
$\mathrm{~N}_{\mathrm{FB} / \mathrm{Arm}}$ & 10 & 5 & 10 \\
$\mathrm{~N}_{\mathrm{HB} / \mathrm{Arm}}$ & 0 & 5 & 0 \\
$\mathrm{C}_{\mathrm{SM}}$ & $1.1 \mathrm{mF}$ & $1.1 \mathrm{mF}$ & $0.5 \mathrm{mF}$ \\
$\mathrm{V}_{\mathrm{SM}}$ & $150 \mathrm{~V}$ & $150 \mathrm{~V}$ & $120 \mathrm{~V}$ \\
$\mathrm{~L}_{\mathrm{PHASE}}$ & $0 \mathrm{mH}$ & $0 \mathrm{mH}$ & $24 \mathrm{mH}$ \\
$\mathrm{L}_{\text {ARM }}$ & $24.3 \mathrm{mH}$ & $24.3 \mathrm{mH}$ & $1.3 \mathrm{mH}$ \\
$\mathrm{L}_{\mathrm{DC}}$ & $0 \mathrm{mH}$ & $0 \mathrm{mH}$ & $3.7 \mathrm{mH}$ \\
\hline
\end{tabular}

TABLE I: Converter Specification 
fault scenarios, according to the programming of the auxiliary converters, as described in [13].

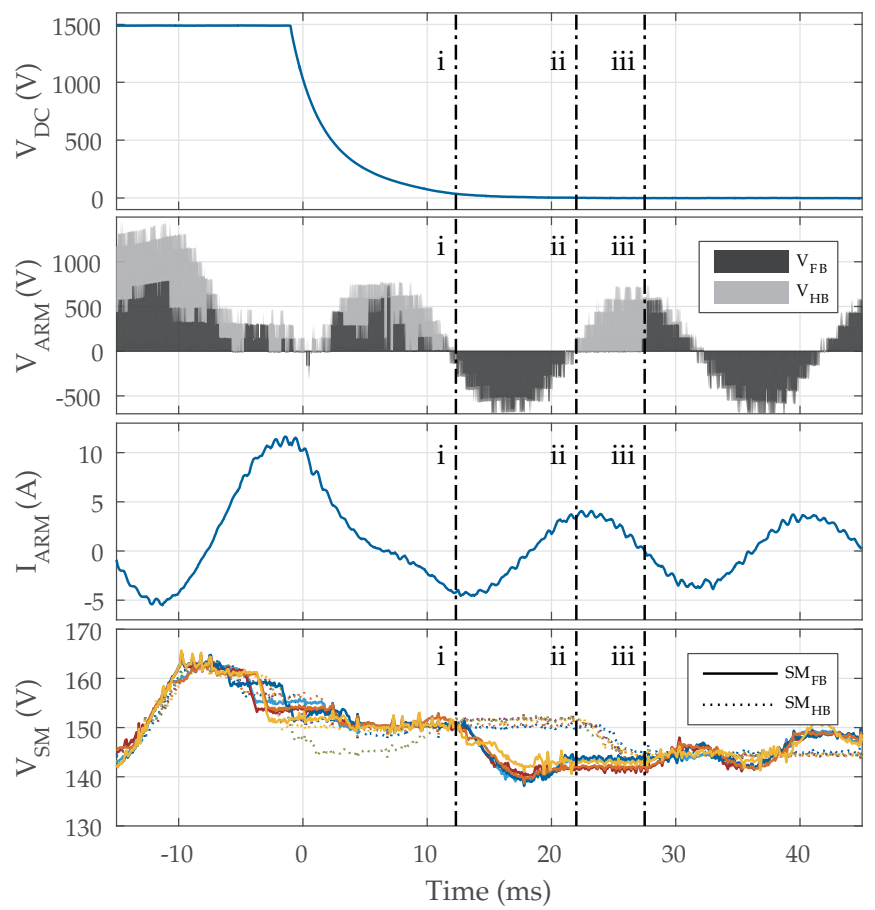

Fig. 4: Experimental results from a mixed stack MMC DC fault: focus on low level control within phase A upper arm $(\mathrm{A}+)$

Whilst full-scale converters consist of many more SMs than can be evaluated with a lab-scale demonstrator, the scale presented here is appropriate for evaluating control and topological principles. Some aspects are not representative of a full-scale converter; for example the losses cannot be considered representative without non-linear scaling and therefore will not be evaluated in this paper.

With a focus on DC fault behaviour, this paper uses one $5 \Omega$ resistor per pole to emulate the fault, resulting in a $15 \mathrm{pu}$ peak fault current. The auxiliary power converters and power supplies on the DC-side are protected from the fault using anti-parallel thyristors. Each converter topology is evaluated under a $200 \mathrm{~ms}$ DC-side pole-to-pole fault, during which the converter maintains its pre-fault reactive power order whilst reducing the real power to zero. The real power reference is slowly increased and the voltage is monitored to determine if the fault has been cleared. After the fault clearance is detected the converter re-charges the DC-side capacitance and resumes the pre-fault power transfer. The fault trigger is not fed to the converter control and therefore the fault response is wholly based on observed measurements. Each fault is triggered at the peak arm current (for the arm shown) in order to best show the lack of fault current contribution from the converter.

Control is achieved through use of an OPAL-RT realtime computing system, allowing the controller to be quickly adapted for different control schemes. The discrete time controller for each topology operates at $10 \mathrm{kHz}$. Throughout all re- sults the arm voltage, DC current and DC voltage are measured using oscilloscope probes, whilst all other measurements are acquired through the controller. All presented measurements are normalised to the point of fault detection.

A $210 \mu \mathrm{F}$ capacitor is present at the DC-side of each converter. In the experimental setup presented, this capacitor does not impact the operation of the converter, given that the DC-side of the converter is connected to a power supply acting as a constant voltage source. At the moment of fault inception, the DC-side capacitance rapidly discharges into the fault, at a peak current defined by the DC voltage and the fault resistance, and for a period defined by the capacitance and the fault resistance $(\tau=R / C)$. This capacitance could represent the capacitance of an HVDC cable connected to the converter. It is noted that there is no fault current contribution from the $\mathrm{AC}$-side of the converter in any of the results presented.

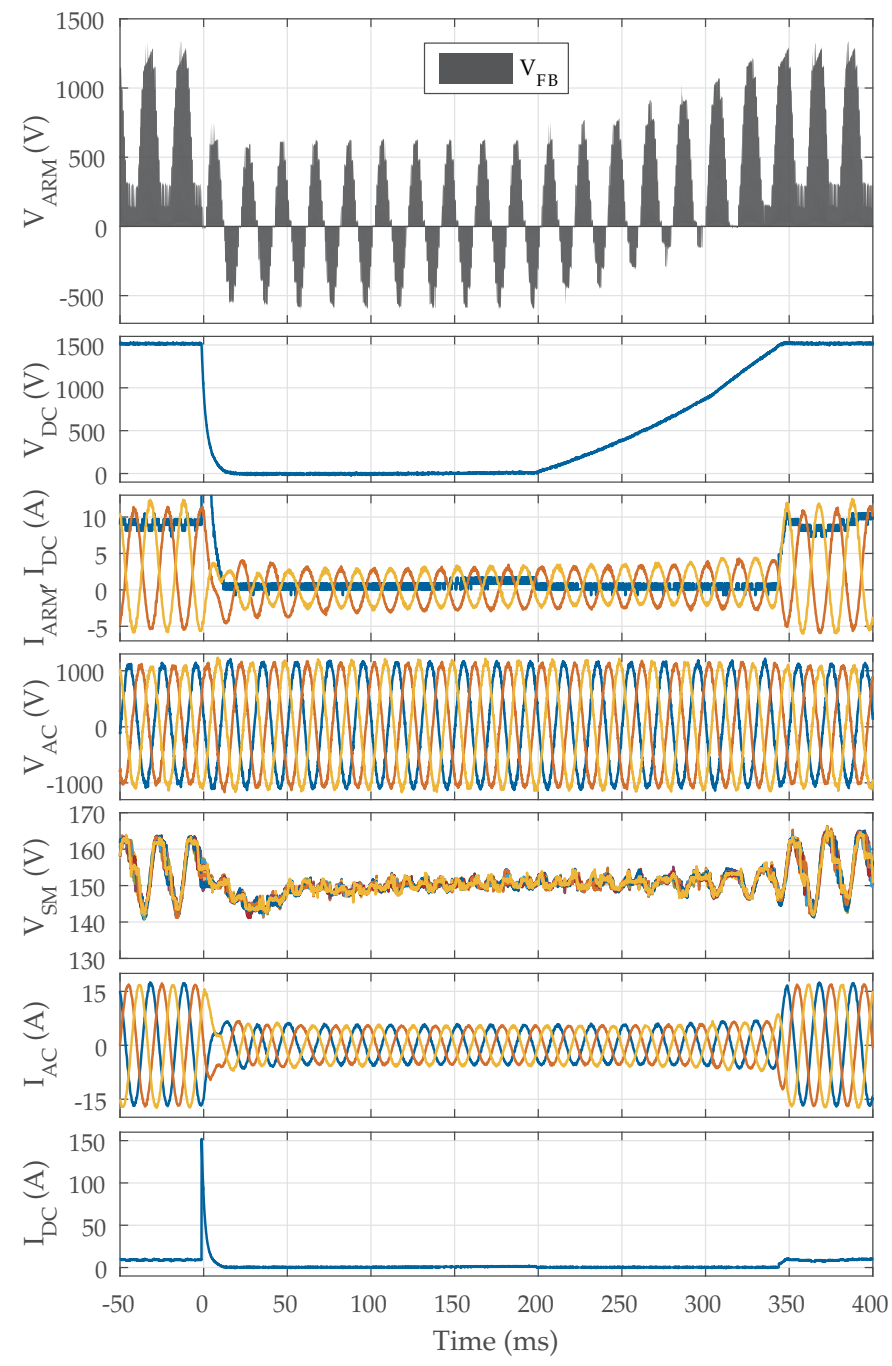

Fig. 5: Experimental results for a full bridge MMC DC fault

\section{A. Low Level Control}

The voltage balancing within a stack is carried out by a combination of sorting algorithms and availability matrices 
to determine the required SM insertion order. For a full bridge MMC or an AAC each SM can insert a positive or negative voltage, and a sorting function determines which SMs should be inserted according to their state of charge and the momentary direction of the arm current. For a mixed stack MMC an availability matrix for both positive and negative SM states is formed, allowing only full-bridge SMs to be used for negative insertion. The converter uses a 'last SM PWM' switching control due to the relatively small number of SMs compared to a full scale converter. When required, one SM in each arm operates in a PWM switching state to achieve the stack voltage ordered of the arm, leading to better current control. This is a caveat of using a demonstrator of this size, and would not be required in a full scale converter.

An example of the balancing conducted by this low level control is shown in Fig. 4, in which a DC fault on a mixed stack MMC is presented. During the DC fault the arms are ordered to over-modulate, inserting the full bridge SMs in the negative state and discharging the SM capacitors accordingly given that the arm current is negative, observed in the phase A upper arm at time marker (i). $21 \mathrm{~ms}$ after fault inception the arm voltage order turns positive and given the current direction the inserted SMs will be discharged, therefore the SMs with the highest voltages (in this instance the half bridge SMs) are chosen for insertion, time marker (ii). When the arm current becomes negative (time marker (iii)) the inserted SMs will now be charged, therefore the SMs with the lowest voltage (in this instance the full bridge SMs) are inserted.

\section{Full Bridge Modular Multilevel Converter}

The full bridge MMC is one of the most commonly considered converters capable of controlling the current into a DC fault. Given that each SM can either be bypassed, inserted in positive or inserted in negative, the converter has the capability to over-modulate and generate either a positive or a negative voltage with each arm. Fig. 5 shows the full set of experimental results. When a DC fault is detected the converter overmodulates to maintain current control throughout the fault event. The power reference is rapidly reduced in magnitude such that only reactive power is maintained to support the connected AC system. The SM voltages experience very little perturbation during and after the fault, and it is observed that there is no noticeable fault current contribution from the converter given that full current control is maintained throughout the test.

\section{Mixed Stack Modular Multilevel Converter}

The mixed stack MMC under test consists of five full bridge and five half bridge SMs per arm, allowing for some overmodulation whilst providing a reduction in losses when compared to the full bridge MMC. Fig. 6 presents the experimental results. Before the fault is triggered, the arm voltage duty is shared between all SMs in the arm, according to voltage balancing requirements. At the moment the fault is detected the converter over-modulates to maintain current control, whilst

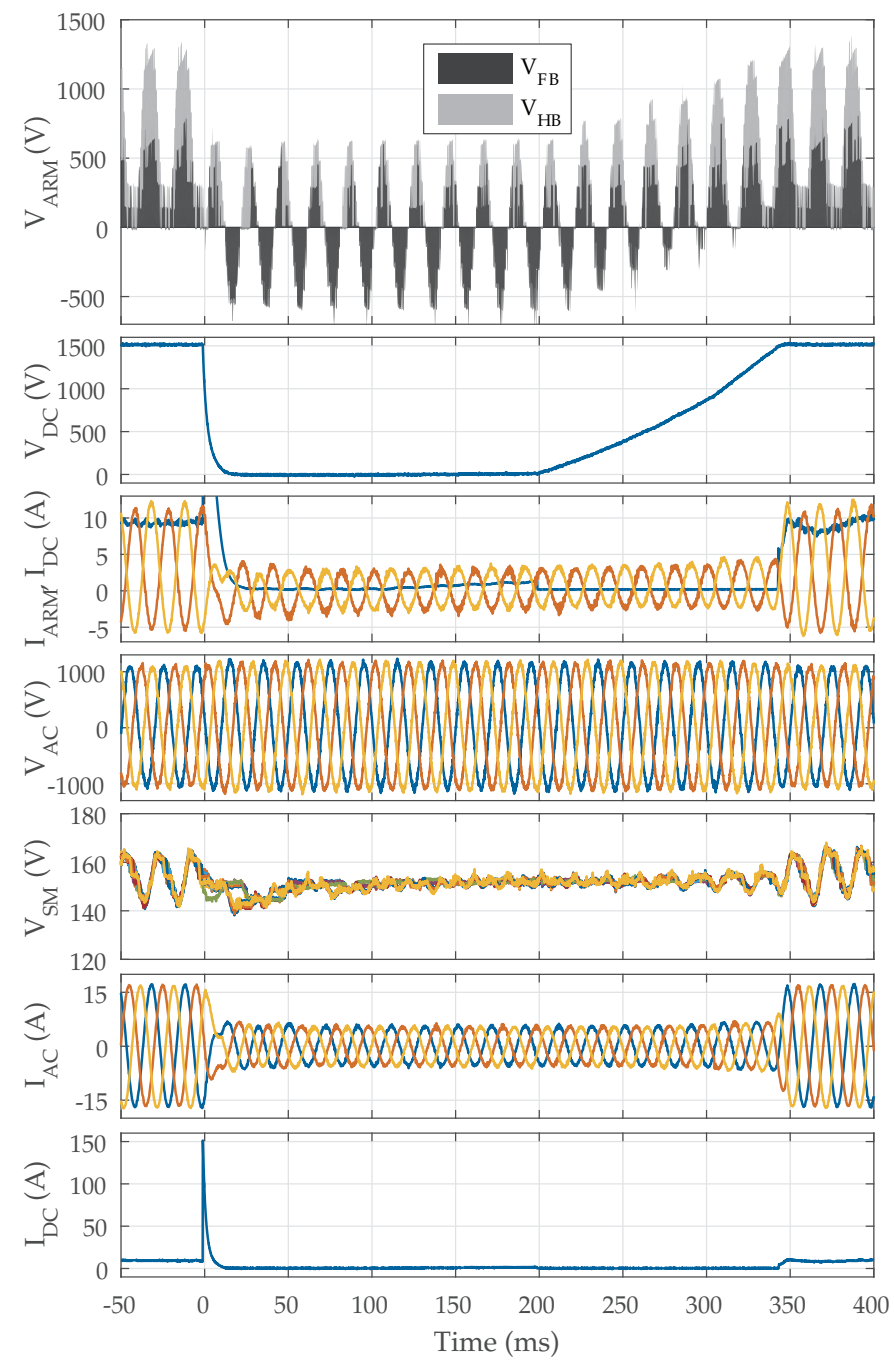

Fig. 6: Experimental results for a mixed stack MMC DC fault

the real power order is reduced to zero. In this mode of operation the full bridge SMs provide the over-modulation function, whilst the positive arm voltage duty is shared between all SMs, again depending on energy balancing requirements. During the fault there is no significant perturbation in SM voltages and there is no noticeable fault current contribution from the converter given that full current control is maintained throughout the test.

\section{Vi. Alternate Arm Converter}

The AAC consists of full bridge SMs and director switches, therefore every SM contributes to any over-modulation required, Fig. 7. In the AAC's extended overlap mode a continuous DC current is achieved, negating the DC-side filter that was required for the short overlap AAC [13], [15]. During normal operation, before the fault is triggered, the over-modulation is only ordered to control the current during the overlap period in which both top and bottom arms within a phase are in conduction. The director switches serve the purpose of blocking additional voltage whilst the arm is not 
in conduction. When the fault is detected the converter moves into over-modulation, during which every SM shares the negative voltage duty and the insertion order is dependent on the energy balancing requirements. Again there is no significant perturbation in SM voltages, and there is no noticeable fault current contribution from the converter given that full current control is maintained throughout the test.
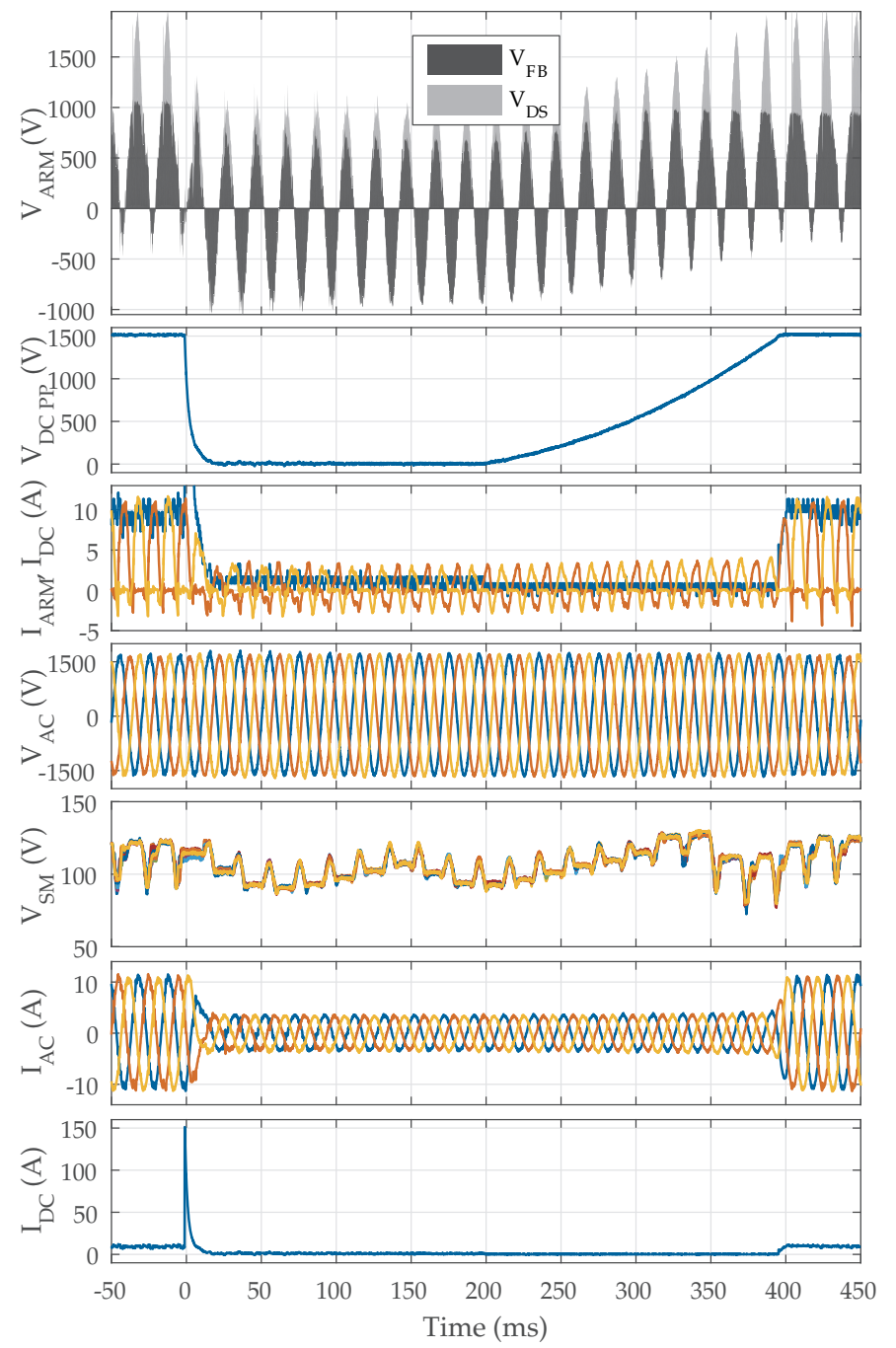

Fig. 7: Experimental results for an alternate arm converter DC fault

\section{CONCLUSION}

Experimental results for the full bridge $\mathrm{MMC}$, the mixed stack MMC and the AAC have been presented, showing that each is capable of maintaining current control before, during and after a DC fault. Throughout all tests balancing algorithms have kept control of the energy in the SMs, drawing balancing currents from the DC-side during normal operation and the AC-side during DC faults. During a DC fault there is no fault current contribution from the converter, as shown by phase and arm currents within the experimental results. There is no requirement to block the IGBTs within the submodules, and because each converter retains full current control throughout the faulted conditions, reactive power can still be supplied and the converter operates in a STATCOM mode, supporting the connected AC system.

\section{ACKNOWLEDGEMENT}

The authors gratefully acknowledge the support provided by EDF Energy R\&D UK and the EPSRC through the industrial CASE scheme, the Hubnet Consortium (EPSRC grant EP/I013636/1), the UK Power Electronic Centre: Converter Theme (ESPRC grant EP/K035096/1), the Top and Tail consortium (EPSRC grant EP/I031707/1) and the cooperation of GE Grid Solutions.

\section{REFERENCES}

[1] W. Zhou, X. Wei, S. Zhang, G. Tang, Z. He, J. Zheng, Y. Dan, and C. Gao, "Development and test of a $200 \mathrm{kV}$ full-bridge based hybrid HVDC breaker," in Power Electronics and Applications (EPE'15 ECCEEurope), 2015 17th European Conference on. IEEE, 2015, pp. 1-7.

[2] W. Grieshaber, J.-P. Dupraz, D. L. Penache, and L. Violleau, "Development and test of a $120 \mathrm{kV}$ direct current circuit breaker," CIGRE session 2014, 2014.

[3] R. Derakhshanfar, T. Jonsson, U. Steiger, and M. Habert, "Hybrid HVDC breaker-A solution for future HVDC system," Cigré Paris Session, paper B4-304, Paris, 2014.

[4] G. Chaffey and T. C. Green, "Reduced DC Circuit Breaker Requirement on Mixed Converter HVDC Networks," in PowerTech (POWERTECH), 2015 IEEE Eindhoven, June 2015.

[5] E. Spahic, F. Schettler, D. Varma, and J. Dorn, "Impact of the DC technology on transmission grids," in $A C$ and DC Power Transmission, 11th IET International Conference on, Feb 2015, pp. 1-7.

[6] M. M. C. Merlin, T. C. Green, P. D. Mitcheson, D. R. Trainer, R. Critchley, W. Crookes, and F. Hassan, "The Alternate Arm Converter: A New Hybrid Multilevel Converter With DC-Fault Blocking Capability,' Power Delivery, IEEE Transactions on, vol. 29, no. 1, pp. 310-317, Feb. 2014.

[7] E. Kontos, R. Pinto, and P. Bauer, "Fast DC fault recovery technique for H-bridge MMC-based HVDC networks," in Energy Conversion Congress and Exposition (ECCE), 2015 IEEE, Sept 2015, pp. 33513358.

[8] A. Nami, A. Hassanpoor, and Y. j. Hfner, "Theory to practical implementation of full-bridge modular multilevel converter for HVDC applications," in 2016 IEEE International Conference on Industrial Technology (ICIT), March 2016, pp. 378-383.

[9] C. Petino, M. Heidemann, D. Eichhoff, M. Stumpe, E. Spahic, and F. Schettler, "Application of multilevel full bridge converters in hvdc multiterminal systems," IET Power Electronics, vol. 9, no. 2, pp. 297 304, 2016.

[10] R. Marquardt, "Modular Multilevel Converter topologies with DC-Short circuit current limitation," in Power Electronics and ECCE Asia (ICPE ECCE), 2011 IEEE 8th International Conference on, May 2011, pp. $1425-1431$

[11] C. Chen, G. Adam, S. Finney, J. Fletcher, and B. Williams, "H-bridge modular multi-level converter: control strategy for improved DC fault ride-through capability without converter blocking," Power Electronics, IET, vol. 8, no. 10, pp. 1996-2008, 2015.

[12] R. Zeng, L. Xu, L. Yao, and D. J. Morrow, "Precharging and dc fault ride-through of hybrid mmc-based hvdc systems," IEEE Transactions on Power Delivery, vol. 30, no. 3, pp. 1298-1306, 2015.

[13] P. D. Judge, G. Chaffey, P. Clemow, M. M. Merlin, and T. C. Green, "Hardware testing of the alternate arm converter operating in its extended overlap mode," in HVDC 2015, International Conference on, 2015.

[14] P. Clemow, P. Judge, G. Chaffey, M. Merlin, T. Luth, and T. Green, "Labscale experimental multilevel modular HVDC converter with temperature controlled cells,' in Power Electronics and Applications (EPE'14ECCE Europe), 2014 16th European Conference on, Aug 2014, pp. $1-10$.

[15] D. Trainer, M. M. C. Merlin, T. C. Green, and D. Soto-Sanchez, “Converter," 2013, patent PCT/EP2011/060907. 